\title{
A single dose of tramadol in continuous wound analgesia with levobupivacaine does not reduce post-sternotomy pain: a randomized controlled trial
}

This article was published in the following Dove Press journal:

Journal of Pain Research

\author{
Floriane Bethenod (D) \\ Omar Ellouze (D) \\ Vivien Berthoud' \\ Anis Missaoui ${ }^{1}$ \\ Amélie Cransac (1D) ${ }^{2}$ \\ Serge Aho $\mathbb{D i D}^{3}$ \\ Olivier Bouchot ${ }^{4}$ \\ Claude Girard' \\ Pierre Grégoire Guinot $\mathbb{D D}^{\prime}$ \\ Belaid Bouhemad' \\ 'Service d'Anesthésie Réanimation, Unité \\ d'Anesthésie Réanimation Cardio \\ Vasculaire, Centre Hospitalier \\ Universitaire de Dijon, Dijon, France; \\ ${ }^{2}$ Pharmacie Centrale, Centre Hospitalier \\ Universitaire de Dijon, Dijon, France; \\ ${ }^{3}$ Service d'Epidémiologie et d'Hygiène \\ Hospitalières, Centre Hospitalier \\ Universitaire de Dijon, Dijon, France; \\ ${ }^{4}$ Service De Chirurgie Cardiaque, \\ Vasculaire Et Thoracique, Centre \\ Hospitalier Universitaire De Dijon, Dijon, \\ France
}

Correspondence: Omar Ellouze Service d'Anesthésie Réanimation, Unité d'Anesthésie Réanimation Cardio Vasculaire, Centre Hospitalier Universitaire de Dijon, BP 77908, Dijon Cedex 21709, France

Tel +33695085389

Email mohamedomar.ellouze@chudijon.fr
Background: Medial sternotomy is commonly used in cardiac surgery, although it results in intense post-operative pain. The placement of a sternal wound catheter for the administration of local anesthetic represents an effective technique. An initial bolus of tramadol in the sternal wound catheter could potentiate the effect of the local anesthetic and decrease both the post-operative pain and the morphine consumption.

Patients and methods: We conducted a prospective, randomized, double-blind study at the University Hospital Center, Dijon, France. Patients requiring scheduled or non-extreme emergency surgery for valve disease, aorta disease, atrial myxoma, or coronary artery bypass graft via sternotomy were included. A sternal wound catheter was inserted at the end of the surgery. The patients were randomized to receive either a $2 \mathrm{mg} / \mathrm{kg}$ bolus of tramadol $(\mathrm{n}=80)$ or a placebo $(n=80)$ in the wound catheter. The bolus administration was followed by a continuous infusion of $1.25 \%$ levobupivacaine for the first $48 \mathrm{hrs}$ following surgery. The patients' morphine consumption during the first $48 \mathrm{hrs}$ after extubation was recorded. The other investigated variables were the patients' rescue analgesia, arterial blood gasses, and length of stay in the intensive care unit and in hospital, as well as the incidence of chronic pain at the four-month follow-up point.

Results: The morphine consumption was found to be comparable in the two groups ( $38 \mathrm{mg}$ vs $32 \mathrm{mg}, p=0.102$ ). No effect was found in terms of the arterial blood gasses, lengths of stay, or incidence of chronic pain.

Conclusion: The addition of tramadol to the local anesthetic delivered via a wound catheter following sternotomy did not reduce the patients' post-operative morphine consumption.

Trial registration: Clinicaltrials.gov identifier: NCT02851394.

Keywords: sternotomy, cardiac surgery, post-operative pain, tramadol

\section{Introduction}

Medial sternotomy remains the most frequently used approach for cardiac surgery despite the emergence of new and less invasive surgical techniques that can be performed by mini-thoracotomy. Sternotomy can result in deep and intense postoperative pain, which is exacerbated by breathing movements, coughing, and respiratory physiotherapy. ${ }^{1}$ Uncontrolled pain can have significant repercussions for a patient's respiratory, cardiovascular, and cognitive function, in addition to increasing both the risk of morbidity and the length of the patient's hospital stay. ${ }^{2}$ The guidelines recommend multimodal pain management that comprises locoregional and systemic analgesia., ${ }^{3,4}$ The continuous infusion of local anesthetic at the 
sternotomy site via a catheter inserted by the surgeon has been found be an effective technique associated with decreased post-operative pain and decreased morphine consumption. $^{5-9}$

Tramadol is generally administered systemically, but when combined with local anesthetic, it accelerates the onset of anaesthesia and prolongs the action of the plexus blockade. $^{10,11}$ Tramadol's action on the peripheral nerve is similar to that of local anesthetic, as it blocks the sodium channels and seems to exert an effect on the peripheral $\mu$-opioid receptors expressed as a result of the inflammatory response, which occurs at the site of the surgical wound. ${ }^{12-14}$ It has been suggested that locally administered tramadol may be just as effective as a local anaesthetic. ${ }^{15-18}$

The aim of this study was to determine whether a bolus of tramadol administered in combination with local anesthetic via a wound catheter reduced patients' consumption of morphine when compared to the administration of local anesthetic alone following cardiac surgery by means of medial sternotomy.

\section{Patients and methods}

\section{Design and patients}

This clinical trial was approved by both the Ethics Committee CPP EST I (Dijon, France, EudraCT N: 2015000213-42) and the Drug Safety Agency (ANSM). All the study procedures were performed in accordance with the provisions of the Declaration of Helsinki and the Good Clinical Practice guidelines. The study was also registered at www.clinicaltrial.gov (Study ID: NCT02851394).

The current single-center, prospective, randomized, double-blind study was conducted at Dijon University Hospital, Burgundy, France, between October 2015 and October 2016. Patients requiring scheduled or non-urgent surgery for valve disease, aorta disease, atrial myxoma, or coronary artery bypass graft via medial sternotomy were included in the study. The exclusion criteria were patients who underwent redo surgery following previous sternotomy and patients with a known hypersensitivity to any of the products used in the present study. We further excluded patients with local or generalized bacterial infection and those with a history of any neurological disorders, acute intoxication, or an overdose of central nervous system depressants. Patients with a serum creatinine level above $170 \mu \mathrm{mol} . \mathrm{I}^{-1}$, liver failure, porphyria, severe respiratory insufficiency, or severe hypotension were also excluded. Moreover, treatment with antidepressants, antiepileptics, neuroleptics, opiates, or steroidal or non-steroidal antiinflammatory drugs was considered another reason for exclusion from the study. Finally, adults subject to guardianship, persons without health insurance cover, and pregnant or breast-feeding women were also excluded from the study.

\section{Study procedure}

The patients were informed about the study protocol during the preoperative anaesthesia consultation. Written informed consent was obtained from all the patients on the day before surgery. The study randomization was stratified by sex, the EuroSCORE II risk, and the surgery time slot (morning or afternoon) prior to each patient's entrance to the operating room. The medical and paramedical teams in the intensive care unit (ICU) and the surgeons were all blind as to the allocated treatment. The patients' premedication consisted of hydroxyzine associated (or not) with a benzodiazepine both the day before and on the morning of the intervention. Pregabalin and gabapentin were forbidden during the study.

General anaesthesia was induced via a target-controlled infusion of propofol and sufentanil. A bolus of cisatracurium $(0.15 \mathrm{mg} / \mathrm{kg})$ was realized prior to tracheal intubation. In the absence of any contra-indication, tranexamic acid was injected. Antibiotic prophylaxis was realized with cefamandole or vancomycin in case of allergy. Arterial and central venous catheters were inserted. Anaesthesia was maintained using a halogenated anesthetic at a minimum alveolar concentration (MAC) of 0.8 for myocardial preconditioning with sufentanil and curare given as a bolus or via a continuous infusion. The hypnotic was replaced with propofol by means of a target-controlled infusion after the start of the cardiopulmonary bypass.

At the end of the surgery, the surgeon inserted a wound catheter (InfiltraLong 150 set catheter with a $19 \mathrm{G} / 150 \mathrm{~mm}$ Alene needle, Gamida, France) into the subcutaneous space following the closing of the sternum. The catheter was purged with $10 \mathrm{~mL}$ of $0.5 \%$ levobupivacaine. On admission to the ICU, the patients were given either a bolus of tramadol as a local infusion at a dose of $2 \mathrm{mg} / \mathrm{kg}$ or $0.9 \%$ saline via a syringe filled to $10 \mathrm{~mL}$. The syringe was prepared and sterilized by the pharmacy following the attribution of the batch using Tenalea randomization software. The bolus was administrated by the ICU nurse, who was blind to the allocated syringe. Once the bolus had been given, the wound catheter was linked to an elastomeric pump (Multirate Infusor LV $5712 \mathrm{~mL} / \mathrm{h}$, Baxter) filled with 
$0.125 \%$ levobupivacaine. The portable diffuser administered the local anesthetic at a rate of $12 \mathrm{~mL} / \mathrm{h}$ until extubation, and then at a rate of $7 \mathrm{~mL} / \mathrm{h}$ for the first $48 \mathrm{hrs}$ following extubation. After this period, the catheter was removed. Systemic analgesia was achieved with paracetamol ( $1 \mathrm{~g}$ every $6 \mathrm{hrs})$ and a titration of morphine ( $2 \mathrm{or} 3 \mathrm{mg}$ every 7 mins) until the patient reached a visual analog scale for pain (VAS) of less than $30 \mathrm{~mm}$. At this point, the patientcontrolled analgesia (PCA) with morphine was initiated. The PCA was set for boluses of $1 \mathrm{mg}$ of morphine, and the refractory period was set as 10 mins. If the patient was still in pain, the protocol included the oral or intravenous administration of $50 \mathrm{mg}$ or $100 \mathrm{mg}$ of ketoprofen or an intravenous bolus of $20 \mathrm{mg}$ of nefopam, which was to be repeated as necessary.

\section{Outcomes}

The primary endpoint was the patients' post-operative morphine consumption during the first $48 \mathrm{hrs}$ following extubation. The secondary endpoints were the evaluation of the rescue analgesia with nefopam or ketoprofen. We also compared the patients' post-operative respiratory parameters using the arterial blood gasses, namely the arterial partial pressure of oxygen (PAO2), arterial oxygen saturation (SO2), and arterial partial pressure of carbon dioxide (PACO2) during the first $48 \mathrm{hrs}$. The Ramsay score during the first $48 \mathrm{hrs}$ following extubation was recorded. Further, any catheterrelated post-operative infections were recorded. We also recorded the patients' post-operative length of stay in the ICU and in the hospital. Finally, we used the Douleur Neuropathique 4 (DN4) questionnaire some 4 months after the surgery to evaluate the incidence of chronic pain. ${ }^{19}$

\section{Data collection}

The clinical data, including the patients' daily consumption of morphine, were recorded, with the initial titration recorded at extubation $\mathrm{H} 0$, then at $\mathrm{H}+6 \mathrm{hrs}, \mathrm{H}+24 \mathrm{hrs}$, and $\mathrm{H}+48 \mathrm{hrs}$. The time between the titration and the first bolus delivered by the PCA was also recorded. Data concerning the static and dynamic pain, as evaluated using the VAS, were collected at extubation, at $\mathrm{H}+6 \mathrm{hrs}$, and then every $12 \mathrm{hrs}$ for the first $48 \mathrm{hrs}$ following extubation. The type and the total dose of rescue analgesia were also recorded during the first $48 \mathrm{hrs}$. The level of sedation was evaluated using the Ramsay scale at $\mathrm{H}+6$ hrs following extubation, and then every $12 \mathrm{hrs}$ for $48 \mathrm{hrs}$. The arterial blood gasses were measured at $\mathrm{H}+6 \mathrm{hrs}$ after extubation, and then once per day over the 2 days following the surgery.
Local post-operative infections were recorded if the patient required revisit surgery for lavage associated with antibiotic therapy during the hospital stay. The study investigators contacted the patients by telephone 4 months after the surgery to complete the DN4 questionnaire so as to evaluate the incidence of chronic pain.

\section{Statistical analysis}

Based on the principal endpoint, we hypothesized that there would be a difference of $30 \%$ in the mean consumption of morphine (30 mg vs $21 \mathrm{mg}$ ) between the placebo and the tramadol groups, respectively, as well as a standard deviation of $20 \mathrm{mg}$, with a bilateral alpha risk of $5 \%$ and a power of $80 \%$. The number of patients calculated according to the above hypotheses was 78 per group, resulting in a total of 156 patients. The statistical analyses were performed on an intention-to-treat basis. The mean consumptions of morphine in the two groups were compared via an analysis of variance or a non-parametric Kruskal-Wallis test (if the conditions of application for the analysis of variance were not respected). The same approach was used for the continuous variables associated with the secondary endpoints. The discrete variables, including the numbers of post-operative infections and the Ramsay scores in the two groups, were compared using a Poisson regression model or a binomial regression model.

\section{Results}

We assessed 171 patients with regard to their eligibility to participate in the present study. One patient did not meet the inclusion criteria, three patients refused to participate, two patients were switched to mini-thoracotomy valve replacement surgery, and five patients were excluded for other reasons. We finally included 160 patients who underwent surgery between October 2015 and October 2016. The study protocol was not respected in 18 patients: three due to them undergoing early redo surgery as a result of active bleeding or tamponade, 13 due to the non-insertion of the wound catheter or the dysfunction of the device, and two due to absence or an error concerning the injection of the tramadol bolus (Figure 1). The wound catheter was withdrawn early in 47 patients for various reasons, including an error in the execution of the protocol, delayed redo surgery during the first $48 \mathrm{hrs}$, the mobilization of the patient, and the premature emptying of the elastomeric pump. The two groups were comparable, save for the mitral valve surgery (Table 1). 


\section{CONSORT 2010 Flow Diagram}

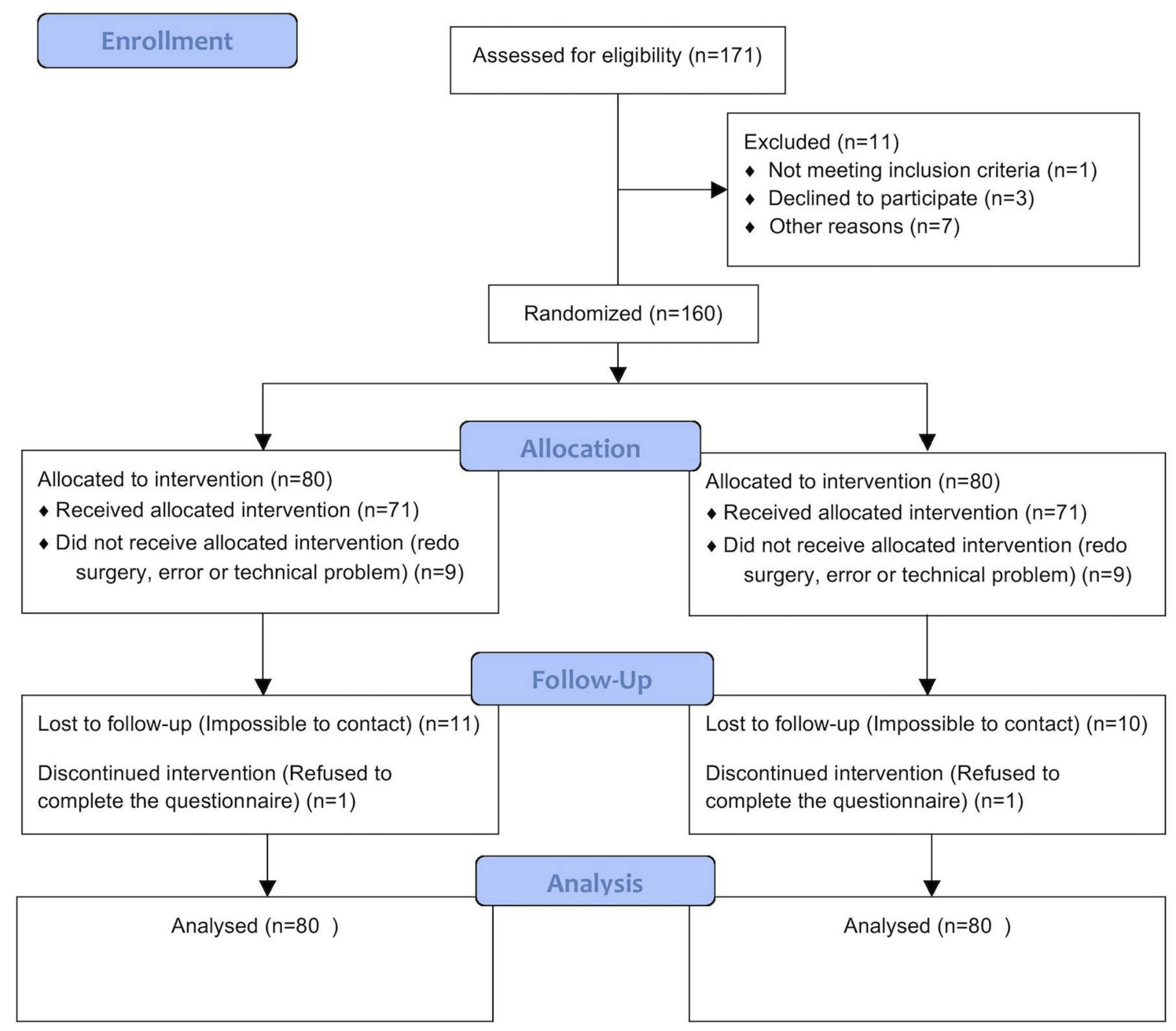

Figure I Flow chart.

\section{Post-operative analgesia}

On an intention-to-treat basis, there was no significant difference found between the two groups in terms of the morphine consumption during the first $48 \mathrm{hrs}$ after the surgery ( $38 \mathrm{mg}$ vs $32 \mathrm{mg}, p=0.102$ ). The difference in the delay in the first use of morphine following titration was also not significantly different (165 $\mathrm{min}$ vs $172 \mathrm{~min}, p=0.814$ ) (Table 2 ). The morphine consumption reached a maximum at $24 \mathrm{hrs,}$, without any significant difference being found at any time between the two groups (Figure 2). The rescue analgesia with ketoprofen or nefopam, as well as the incidence of chronic pain at 4 months, were again not significantly different between the two groups (Table 2). With regard to the findings concerning the arterial blood gasses, the PAO2/FIO2 ratios were not significantly different between the two groups $(p=0.088)$, nor were the PACO 2 findings ( $p=0.858$ ) (Figure 3 ). The Ramsay scores were comparable in the two groups during the first 48 hrs $(p=0.984)$ (Figure 4).

\section{Recovery and complications}

The post-operative recovery was found to be almost identical in the two groups. The mean duration of the ICU stay was 4 days for the placebo group and 3.6 days for the tramadol group ( $p=0.603$ ), while the mean duration of the hospital stay was 10.3 days for the placebo group and 10.1 days for the tramadol group $(p=0.321)$ (Table 3). From October 2015 to May 2016, the incidence of repeat sternal surgery due to mediastinitis was $4.4 \%$ in our study, as compared to $6.1 \%$ in patients who did not receive a wound catheter $(p=0.526)$. 
Table I Demographic, anesthetic and surgical characteristics

\begin{tabular}{|c|c|c|c|}
\hline & $\begin{array}{l}\text { Tramadol } \\
(n=80)\end{array}$ & $\begin{array}{l}\text { Placebo } \\
(n=80)\end{array}$ & $P$ \\
\hline Age (years) & $67[6 \mathrm{I}-76]$ & $67[6 I-77]$ & 0,89 \\
\hline Male (\%) & 65 (81.3\%) & 69 (86.3\%) & 0.83 \\
\hline ASA & $2.8[3-3]$ & $2.8[3-3]$ & 0.85 \\
\hline Euroscore II & $2.1[0.86-2.86]$ & $2[0.72-2.85]$ & 0.45 \\
\hline Diabetes & $24(30 \%)$ & 21 (26.3\%) & 0.73 \\
\hline Benzodiazepines & 7 (8.7\%) & II (I3.7\%) & 0.45 \\
\hline Long-term analgesics & $5(6.2 \%)$ & $7(8.7 \%)$ & 0.77 \\
\hline \multicolumn{4}{|l|}{ Type of intervention } \\
\hline Aortic valve surgery & $28(35 \%)$ & $30(37.5 \%)$ & 0.87 \\
\hline Mitral valve surgery & $3(3.7 \%)$ & II (I3.7\%) & 0.05 \\
\hline $\begin{array}{l}\text { Coronary artery } \\
\text { bypass graft }\end{array}$ & 59 (73.7\%) & $63(78.7 \%)$ & 0.59 \\
\hline Aortic surgery & 14 (I7.5\%) & 9 (I I.2\%) & 0.37 \\
\hline $\begin{array}{l}\text { Duration of intervention } \\
\text { (min) }\end{array}$ & 228 [197-259] & 238 [207-273] & 0.10 \\
\hline CPB time (min) & $93[66-125]$ & 99 [82-128] & 0.60 \\
\hline Aortic clamp time (min) & 71 [45-98] & 73 [59-97] & 0.83 \\
\hline Sufentanil ( $\mu g$ ) & $123[105-143]$ & $124[102-139]$ & 0.86 \\
\hline $\begin{array}{l}\text { Duration of anaesthesia } \\
\text { (min) }\end{array}$ & 586 [502-633] & 637 [5|4-697] & 0.35 \\
\hline
\end{tabular}

Notes: The quantitative data are expressed as median [IQR]. Qualitative data are expressed as $n(\%)$.

Abbreviation: $C B P$, cardiopulmonary bypass.

\section{Discussion}

The main finding of the present study is that an initial bolus of $2 \mathrm{mg} / \mathrm{kg}$ of tramadol given in the sternal wound catheter associated with continuous suprasternal analgesia

Table 2 Post operative analgesia

\begin{tabular}{|c|c|c|c|}
\hline & $\begin{array}{l}\text { Tramadol } \\
(n=80)\end{array}$ & $\begin{array}{l}\text { Placebo } \\
(n=80)\end{array}$ & $\boldsymbol{P}$ \\
\hline $\begin{array}{l}\text { Morphine consumption during } \\
\text { the first } 48 \mathrm{hrs}(\mathrm{mg})\end{array}$ & $38[17-53]$ & $32[14-49]$ & 0.10 \\
\hline $\begin{array}{l}\text { Time between morphine } \\
\text { infusion and Ist bolus of the } \\
\text { PCA (min) }\end{array}$ & $165 \pm 179$ & $172 \pm 196$ & 0.81 \\
\hline Rescue analgesia & 15 (I8.7\%) & $16(20 \%)$ & 1 \\
\hline Chronic pain at 4 months & I (I.25\%) & $\mathrm{I}(\mathrm{I} .25 \%)$ & 0.28 \\
\hline
\end{tabular}

Notes: The quantitative data are expressed as median [IQR]. Qualitative data are expressed as $n(\%)$. by means of levobupivacaine did not significantly reduce patients' morphine consumption during the first $48 \mathrm{hrs}$ after medial sternotomy when compared to wound analgesia achieved with levobupivacaine alone. Moreover, this treatment did not result in a reduction in chronic pain at the four-month follow-up point.

Sternotomy induces intense post-operative pain, mainly in the wound site and the shoulders. ${ }^{20}$ In this case, the post-operative analgesia is based on multimodal analgesia that can associate locoregional anaesthesia with systemic analgesics. $^{3,4}$ The infusion of local anesthetic into the wound via a catheter inserted by the surgeon is a welltolerated and straightforward procedure. Several studies have suggested the analgesic efficacy of a wound catheter following heart surgery via sternotomy in terms of a reduction in patients' morphine consumption. ${ }^{5,8,9,21}$

Tramadol has traditionally been systemically administered, although its indication has now been extended to locoregional anaesthesia. Tramadol acts by blocking the nerve conduction. The reversible inhibition of the sodium channels prevents the propagation of action potentials during painful stimulation, thereby mimicking the mechanism of local anaesthetic. ${ }^{12,13}$ Tramadol may also inhibit the nociceptive behavior mediated by peripheral glutamate. ${ }^{22}$ Additionally, it seems to act on the peripheral $\mu$ receptors, which are expressed during the inflammatory response. ${ }^{14}$ The efficacy of tramadol infiltrations into the gums or nose has been shown to be comparable to that of lidocaine. ${ }^{23,24}$ Further, the analgesia induced by tramadol administered locally following abdominal surgery was found to be better than that achieved with bupivacaine or levobupivacaine. It also allowed for longer post-operative analgesia and a reduction in morphine consumption. ${ }^{17,18}$ The efficacy of the combination of tramadol and levobupivacaine in a plexus block has previously been demonstrated. ${ }^{25-27}$ The intramuscular or perineural injection of tramadol potentiates local anesthetic, as shown by Alemanno et al in the case of an interscalene block. ${ }^{25}$ Moreover, the combination of tramadol and levobupivacaine induced longer analgesia than levobupivacaine alone when used for a caudal block during inguinal hernia surgery. ${ }^{26}$

We chose to deliver this combination of tramadol and levobupivacaine via a single multi-perforated wound catheter placed over the sternum. Other authors have shown the efficacy of two subcutaneous catheters delivering a local anesthetic placed over the sternum. When compared to a saline infusion, this strategy led to a significant decrease in 


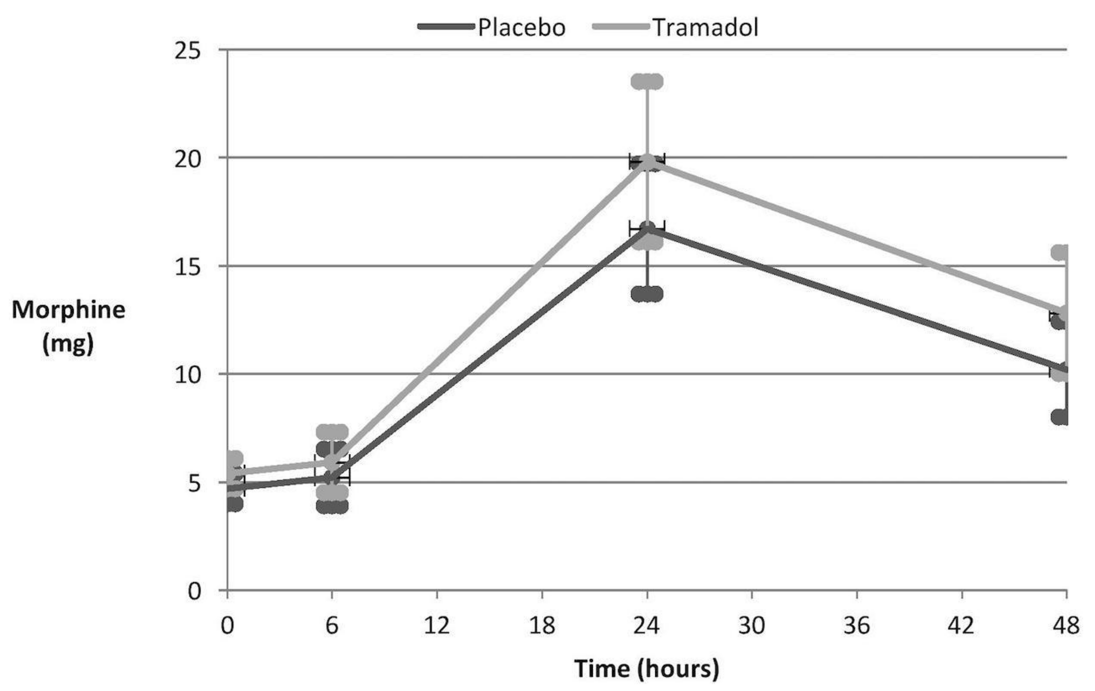

Figure 2 Evolution of the morphine consumption during the first 48 hrs post-surgery.

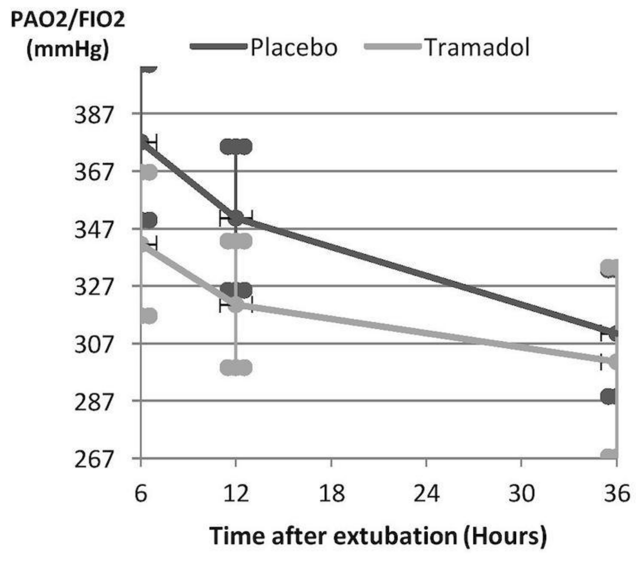

Figure 3 Results concerning the blood gasses during the first 48 hrs post-surgery.

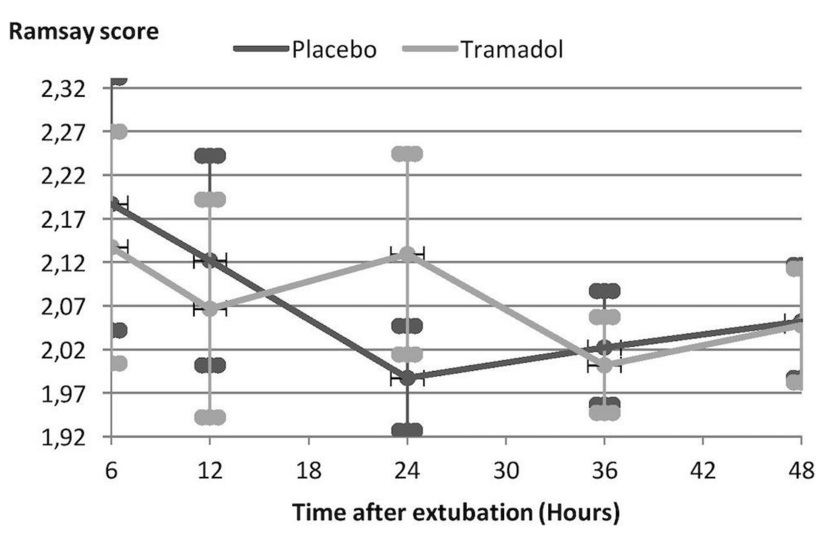

Figure 4 Ramsay scores during the first 48 hrs post-surgery.

patients' post-operative morphine consumption. ${ }^{5,9}$ Eljezi et al placed two catheters over the lateral edges of the sternum, thereby significantly reducing the pain experienced during

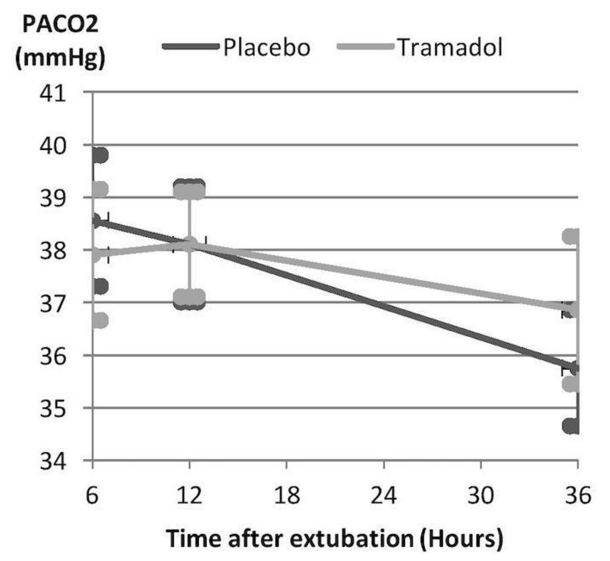

mobilization. ${ }^{21}$ Expert recommendations in this regard include the insertion of a catheter in the presternal or mixed position (a retrosternal or a subcutaneous catheter). ${ }^{4}$

Our principal judgement criterion was the patients' morphine consumption during the first $48 \mathrm{hrs}$ post-surgery, which is considered to be the most painful period. ${ }^{20}$ Our study found no significant difference between the placebo group and the tramadol group. Our results are thus in agreement with those of Ekmekçi et al, who implemented continuous wound analgesia with levobupivacaine alone or in combination with $1 \mathrm{mg} / \mathrm{kg}$ or $2 \mathrm{mg} / \mathrm{kg}$ of tramadol following caesarean section. They reported no significant difference in relation to the total consumption of meperidine. ${ }^{28}$ This finding could be explained by several factors. First, there is currently no consensus as to the best dosage of tramadol for infusions. We arbitrarily chose 
Table 3 Post-operative recovery

\begin{tabular}{|l|l|l|l|}
\hline & Tramadol $(\mathbf{n = 8 0})$ & Placebo $(\mathbf{n}=\mathbf{8 0})$ & $P$ \\
\hline Time to extubation (min) & $283[2$ I0-305] & $316[210-360]$ & 0.62 \\
Time to first mobilization (days) & $0.72[0-1]$ & $0.84[0-1]$ & 0.53 \\
Duration of stay in ICU (days) & $3.6[2-4.5]$ & $4[2-4]$ & $10.3[8-10]$ \\
Duration of stay in hospital (days) & $10.1[8-11]$ & 0.60 \\
\hline
\end{tabular}

Note: Quantitative data are expressed as means [IQR].

$2 \mathrm{mg} / \mathrm{kg}$ based on a review of the literature. ${ }^{18,29}$ The tramadol dose may have been too low. A recent study found no difference in efficacy between a dose of $2 \mathrm{mg}$ / $\mathrm{kg}$ and a dose of $1 \mathrm{mg} / \mathrm{kg}$ of tramadol in combination with levobupivacaine when delivered as an infusion following caesarean section. ${ }^{28}$ Moreover, Robaux et al reported that tramadol increased the duration and also improved the quality of the post-operative analgesia associated with an axillary block in a dose-dependent manner. The doses of tramadol, in combination with mepivacaine, were $40 \mathrm{mg}$, $100 \mathrm{mg}$, or $200 \mathrm{mg} .{ }^{30}$ Furthermore, we decided to administer a bolus of tramadol alone immediately after the surgery. To better evaluate the efficacy of tramadol, it would be useful to leave more time between the end of the surgery and the injection of a bolus of tramadol alone so as to avoid the aspiration of the product by the drainage system. The continuous infusion of a mixture of tramadol and levobupivacaine could also be tested. Finally, it must be remembered that several sites are affected by postoperative pain following sternotomy, that is, not only the wound site, but also the shoulders and the drains. ${ }^{20}$ Severe pain may occur where the saphenous vein was harvested for the coronary artery bypass graft.

It is important to bear in mind that this study had several limitations. First, it was a single-center study reflecting the anesthetic practice of only a single team. Second, there was a selection bias, as our study population was extremely limited due to the exclusion criteria. These exclusion criteria were related to the contra-indications and the risk of drug interactions associated with both tramadol and levobupivacaine. The presence of pre-operative pain requiring regular doses of analgesics and a history of sternotomy are risk factors for post-operative hyperalgesia and the onset of chronic pain. Moreover, the results of our study must be interpreted with caution. Certain methodological shortcomings could explain the lack of a significant difference between the two groups. Indeed, twelve recordings of patients' morphine consumption during the first 48 hrs post-surgery were missing, which led to a loss of power. We also reported the early withdrawal of the catheter in 47 patients, who hence did not receive the local anesthetic for $48 \mathrm{hrs}$. There were various reasons for the early withdrawal of the catheter, including the premature emptying of the elastomeric pump. The reduced duration of the local anesthetic infusion could be explained by the longer interval between admission to the ICU and extubation seen in relation to certain patients, as, during this period, the pump was set at the higher rate of $12 \mathrm{~mL} / \mathrm{h}$. The tramadol administration modality could also explain our results. We chose to administer a single bolus via a single wound catheter. Continuous administration with levobupivacaine might have proven more effective, although the combined stability of tramadol and levobupivacaine remains unknown. Moreover, the tramadol infiltration could be resorbed and have a systemic effect. Finally, the local administration of tramadol appears to exert an effect on the plexus nerve block, and it seems more effective than infiltration alone in terms of blocking the intercostal nerve in our study, which could explain our results. The evaluation of the sensory block and its duration, as compared to the placebo group, could have objectified the blockage of the intercostal nerve by means of the infiltration.

\section{Conclusion}

In our study, an initial infusion bolus of $2 \mathrm{mg} / \mathrm{kg}$ of tramadol followed by continuous suprasternal wound analgesia with levobupivacaine did not reduce the patients' post-operative morphine consumption following heart surgery via sternotomy. The mechanisms of action of tramadol when given as an infusion are not yet fully understood. Complementary studies are, therefore, required to elucidate the local properties of this analgesic and to evaluate it in combination with local anesthetic in other types of surgeries.

\section{Abbreviations}

ICU, intensive care unit; VAS, visual analog scale; PCA, patient-controlled analgesia; $\mathrm{PAO} 2$, arterial partial 
pressure of oxygen; PACO2:, arterial partial pressure of carbon dioxide; FIO2, fraction inspired of oxygen; MAC, minimum alveolar concentration.

\section{Ethics approval and informed consent}

This clinical trial was approved by both the Ethics Committee CPP EST I (Dijon, France, EudraCT N: 2015000213-42) and the Drug Safety Agency (ANSM).

\section{Data sharing statement}

Will individual participant data be available? Yes. What data in particular will be shared? All the individual participant data collected during the trial will be shared following deidentification. What other documents will be available? The study protocol. When will data be available? Immediately following publication. No end date. With whom? Researchers who provide a methodologically sound proposal. For what types of analyses? To achieve the aims of the approved proposal. By what mechanism will data be made available? Proposals should be directed to mohamedomar.ellouze@chu-dijon.fr. To gain access, data requestors will need to sign a data access agreement.

\section{Acknowledgments}

This study was supported by the Centre Hospitalier Universitaire Dijon Bourgogne. Gamida (Eaubonne, France) provided financial support for this study by providing the sternal catheter. However, Gamida had no involvement in the study design, data collection, statistical analysis, data interpretation, or writing and submitting of this article.

\section{Author contributions}

All authors contributed towards data analysis, drafting and critically revising the paper, gave final approval of the version to be published, and agreed to be accountable for all aspects of the work.

\section{Disclosure}

Dr Floriane Bethenod reports non-financial support from Gamida during the conduct of the study. The authors report no other conflicts of interest in this work.

\section{References}

1. Lahtinen P, Kokki H, Hynynen M. Pain after cardiac surgery: a prospective cohort study of 1-year incidence and intensity. Anesthesiology. 2006;105:794-800. doi:10.1097/00000542-200610000-00026
2. Schwann NM, Chaney MA. No pain, much gain? J Thorac Cardiovasc Surg. 2003;126:1261-1264. doi:10.1016/S0022-5223(03)01327-8

3. Recommandations formalisées d'experts 2008. Prise en charge de la douleur postopératoire chez l'adulte et l'enfant. Ann Fr Anesth Réanimation. 2008;27:1035-1041.

4. Fletcher D, Aubrun F. Les textes longs de la recommandation formalisée d'experts sur la prise en charge de la douleur postopératoire. $\mathrm{Ann} \mathrm{Fr}$ Anesth Réanimation. 2009;28:1-2. doi:10.1016/j.annfar.2008.12.001

5. White PF, Rawal S, Latham P, et al. Use of a continuous local anesthetic infusion for pain management after median sternotomy. Anesthesiology. 2003;99:918-923. doi:10.1097/00000542-200310000-00026

6. McDonald SB, Jacobsohn E, Kopacz DJ, et al. Parasternal block and local anesthetic infiltration with levobupivacaine after cardiac surgery with desflurane: the effect on postoperative pain, pulmonary function, and tracheal extubation times. Anesth Analg. 2005;100:25-32. doi:10.1213/01.ANE.0000139652.84897.BD

7. Kocabas S, Yedicocuklu D, Yuksel E, et al. Infiltration of the sternotomy wound and the mediastinal tube sites with $0.25 \%$ levobupivacaine as adjunctive treatment for postoperative pain after cardiac surgery. Eur $J$ Anaesthesiol. 2008;25:842-849. doi:10.1017/S0265021508004614

8. Koukis I, Argiriou M, Dimakopoulou A, et al. Use of continuous subcutaneous anesthetic infusion in cardiac surgical patients after median sternotomy. J Cardiothorac Surg. 2008;3:2. doi:10.1186/1749-8090-3-2

9. Dowling R, Thielmeier K, Ghaly A, Barber D, Boice T, Dine A. Improved pain control after cardiac surgery: results of a randomized, double-blind, clinical trial. J Thorac Cardiovasc Surg. 2003;126:1271-1278. doi:10.1016/S0022-5223(03)00585-3

10. Kaabachi O, Ouezini R, Koubaa W, et al. Tramadol as an adjuvant to lidocaine for axillary brachial plexus block. Anesth Analg. 2009;108:367-370. doi:10.1213/ane.0b013e31818e 0c6b

11. Kapral S, Gollmann G, Waltl B, et al. Tramadol added to mepivacaine prolongs the duration of an axillary brachial plexus blockade. Anesth Analg. 1999;88:853-856. doi:10.1213/00000539-199904000-00032

12. Tsai YC, Chang PJ, Jou IM. Direct tramadol application on sciatic nerve inhibits spinal somatosensory evoked potentials in rats. Anesth Analg. 2001;92:1547-1551. doi:10.1097/00000539-200106000-00040

13. Haeseler G, Foadi N, Ahrens J, et al. Tramadol, fentanyl and sufentanil but not morphine block voltage-operated sodium channels. Pain. 2006;126:234-244. doi:10.1016/j.pain.2006.07.003

14. Gentili M-E, Estèbe J-P. Utilisation clinique du Tramadol [Clinical use of Tramadol]. In: Communications MAPAR. Paris: MAPAR Editions; 1998:233-241. French.

15. Altunkaya H, Ozer Y, Kargi E, et al. Comparison of local anaesthetic effects of tramadol with prilocaine for minor surgical procedures. $\mathrm{Br}$ J Anaesth. 2003;90:320-322. doi:10.1093/bja/aeg079

16. Jabalameli M, Hazegh P, Talakoub R. Preemptive subcutaneous tramadol for post-operative pain in lower abdomen surgeries: a randomized double blinded placebo-control study. Adv Biomed Res. 2013;2:68. doi:10.4103/2277-9175.115816

17. Demiraran Y, Ilce Z, Kocaman B, et al. Does tramadol wound infiltration offer an advantage over bupivacaine for postoperative analgesia in children following herniotomy? Paediatr Anaesth. 2006;16:1047-1050. doi:10.1111/j.1460-9592.2006.01910.x

18. Demiraran Y, Albayrak M, Yorulmaz IS, et al. Tramadol and levobupivacaine wound infiltration at cesarean delivery for postoperative analgesia. J Anesth. 2013;27:175-179. doi:10.1007/s00540-012-1510-7

19. Cruccu G, Sommer C, Anand P, et al. EFNS guidelines on neuropathic pain assessment: revised 2009. Eur J Neurol. 2010;17:10101018. doi:10.1111/j.1468-1331.2010.02969.x

20. Mazzeffi M, Khelemsky Y. Poststernotomy pain: a clinical review. $J$ Cardiothorac Vasc Anesth. 2011;25:1163-1178. doi:10.1053/j.jvca. 2011.08.001

21. Eljezi V, Dualé C, Azarnoush K, et al. The analgesic effects of a bilateral sternal infusion of ropivacaine after cardiac surgery. Reg Anesth Pain Med. 2012;37:166-174. doi:10.1097/AAP.0b013e31824 $0957 \mathrm{f}$ 
22. Wang JT, Chung CC, Whitehead RA, et al. Effects of local tramadol administration on peripheral glutamate-induced nociceptive behaviour in mice. Can J Anesth. 2010;57:659-663. doi:10.1007/s12630-010-9301-9

23. Al-Haideri YAA. Comparison of local anesthetic efficacy of tramadol hydrochloride (with adrenaline) versus plain tramadol hydrochloride in the extraction of upper molar teeth. J Oral Maxillofac Surg. 2013;71:2035-2038. doi:10.1016/j.joms.2013.08.009

24. Koputan $\mathrm{MH}$, Apan A, Oz G, et al. The effects of tramadol and levobupivacaine infiltration on postoperative analgesia in functional endoscopic sinus surgery and septorhinoplasty. Balk Med J. 2012;29:391-394. doi:10.5152/balkanmedj.2012.027

25. Alemanno F, Ghisi D, Fanelli A, et al. Tramadol and $0.5 \%$ levobupivacaine for single-shot interscalene block: effects on postoperative analgesia in patients undergoing shoulder arthroplasty. Minerva Anestesiol. 2012;78:291-296.

26. Yildiz TS, Ozdamar D, Bagus F, et al. Levobupivacaine-tramadol combination for caudal block in children: a randomized, doubleblinded, prospective study. Paediatr Anaesth. 2010;20:524-529. doi:10.1111/j.1460-9592.2010.03296.x
27. Cekic B, Geze S, Erturk E, Akdogan A, Eroglu A. A comparison of levobupivacaine and levobupivacaine-tramadol combination in bilateral infraorbital nerve block for postoperative analgesia after nasal surgery. Ann Plast Surg. 2013;70:131-134. doi:10.1097/SAP.0b013e 318236 baa 8

28. Ekmekçi P, Çağlar GS, Yılmaz H, et al. Effects of different doses of tramadol added to levobupivacaine in continuous wound infusion for postoperative pain treatment following cesarean section. J MaternFetal Neonatal Med. 2017;30:343-346. doi:10.3109/14767058.2016. 1172567

29. Ozyilmaz K, Ayoglu H, Okyay RD, et al. Postoperative analgesic effects of wound infiltration with tramadol and levobupivacaine in lumbar disk surgeries. J Neurosurg Anesthesiol. 2012;24:331-335. doi:10.1097/ANA.0b013e3182611a1d

30. Robaux S, Blunt C, Viel E, et al. Tramadol added to $1.5 \%$ mepivacaine for axillary brachial plexus block improves postoperative analgesia dose-dependently. Anesth Analg. 2004;98:1172-1177. doi:10.1213/01.ane.0000103265.48380.89
Journal of Pain Research

\section{Publish your work in this journal}

The Journal of Pain Research is an international, peer reviewed, open access, online journal that welcomes laboratory and clinical findings in the fields of pain research and the prevention and management of pain. Original research, reviews, symposium reports, hypothesis formation and commentaries are all considered for publication. The manuscript management system is completely online and includes a very quick and fair peer-review system, which is all easy to use. Visit http:// www.dovepress.com/testimonials.php to read real quotes from published authors. 